\title{
A TEORIA DA EDUCAÇÃO DE IMMANUEL KANT E O APERFEIÇOAMENTO MORAL
}

\author{
Immanuel Kant's Theory od Education and Moral Improvement
}

Resumo: O presente artigo pretende analisar a teoria da educação do filósofo Immanuel Kant a fim de compreender como a pode desempenhar papel essencial no aperfeiçoamento da natureza humana com fins a moralidade. Portanto, partimos da seguinte hipótese: a educação, quando pautada no ideal de humanidade, é a chave do aperfeiçoamento moral do homem enquanto espécie humana. Para esse fim, dividimos nosso artigo em duas seções. $\mathrm{Na}$ primeira seção, denominada $A$ teoria $d a$ educação kantiana, aspiramos analisar a teoria da educação kantiana em seus aspectos físico e prático. Na segunda seção, A pedagogia do Esclarecimento, pretendemos compreender como a pedagogia kantiana pode contribuir para a efetivação da autonomia do pensamento e do esclarecimento moral. Logo, buscaremos defender a hipótese de que é possível um modelo de educação com fins ao progresso moral da natureza humana.

Palavras-chave: Immanuel Kant, Educação, Aperfeiçoamento Moral.

\begin{abstract}
This article intends to analyze the theory of the education of the philosopher Immanuel Kant in order to understand how education can play an essential role in the perfection of human nature with morality ends. Therefore, we start from the following hypothesis: education, when based on the ideal of humanity, is the key to the moral perfection of man as a human species. To this end, we divide our article into two sections. In the first section, called the theory of Kantian education, we aspire to analyze the theory of Kantian education in its physical and practical aspects. In the second section, the pedagogy of enlightenment, we intend to understand how Kantian pedagogy can contribute to the realization of the autonomy of thought and moral enlightenment. Therefore, we will try to defend the hypothesis that a model of education is possible for the moral progress of human nature.
\end{abstract}

Keywords: Immanuel Kant, Education, Moral Improvement.

* Mestranda pela Universidade Federal da Paraíba (UFPB - Bolsista Capes). Endereço eletrônico: rafaellasilveir@hotmail.com.

\begin{tabular}{|c|c|c|c|c|c|}
\hline intuitio & $\begin{array}{c}\text { ISSN } \\
1983-4012\end{array}$ & Porto Alegre & Vol.11 $-\mathrm{N}^{\mathrm{o} .2}$ & $\begin{array}{c}\text { Dezembro } \\
2018\end{array}$ & p.66-86 \\
\hline
\end{tabular}




\section{Introdução}

O tema principal de estudo deste trabalho é a filosofia da educação e o aperfeiçoamento moral humano. Mais especificamente, pretende-se compreender a teoria da educação kantiana como meio de desenvolver a perfeição da natureza humana, visto que, segundo Kant, "o grande segredo da perfeição da natureza humana se esconde no próprio problema da educação"1. Assim sendo, o objetivo principal deste trabalho é apreender a importância da educação para a formação da humanidade do homem, sobretudo, em seu aspecto moral. Logo, o problema que pretendemos investigar é o seguinte: como a educação pode contribuir com o aperfeiçoamento da natureza humana? E nessa perspectiva, quais os princípios que devem fundamentar uma educação que vise a inteira destinação da humanidade?

Diante desse problema, a hipótese que tomaremos como resposta provisória dessa investigação é a seguinte: a educação, quando pautada no ideal de humanidade, é a chave do aperfeiçoamento moral do homem enquanto espécie humana. Para defender essa hipótese, nos alicerçamos, sobretudo, na obra Über Pädagogik (1803) ${ }^{2}$ de Immanuel Kant (1724-1804), considerando que, além dessa obra ser a mais específica do filósofo prussiano a tratar do problema da educação, é nela que "Kant aborda de forma precisa o tema Educação, dizendo que é ela que faz do homem um verdadeiro homem. É a Educação que possibilitará ao homem sua evolução até que possa chegar ao seu fim que é ver se enquanto humanidade" ${ }^{3}$. Sem a qual é impossível uma ação verdadeiramente moral. ${ }^{4}$

Nesse contexto, pretendemos ressaltar que não é todo e qualquer modelo educacional que permitirá esse aperfeiçoamento, mas, tão somente, uma educação com fins à liberdade, isto é, um modelo pedagógico que tenha como objetivo dar as condições para o desenvolvimento da

\footnotetext{
${ }^{1}$ KANT, Immanuel. Sobre a pedagogia. Tradução Francisco C. Fontanella. Piracicaba: Editora Unimep, 1999, p. 16.

${ }^{2}$ Sobre a pedagogia. Tradução Francisco C. Fontanella. Piracicaba: Editora Unimep, 1999.

${ }^{3}$ ROSA. Leonardo de Ross. Disciplia, o princípio da educação em Kant. Congresso Internacional de filosofia e educação, Rio Grande do Sul, 2010, p. 2.

${ }^{4} \mathrm{O}$ homem se torna verdadeiramente homem, por meio da educação, porque ela possibilita o aperfeiçoamento, a princípio, da destreza e da prudência e, por sua vez, da moralidade. Neste sentido, apesar do homem nascer homem, enquanto possuidor de dignidade, visto que é um ser racional e, portanto, uma pessoa (possuidor de valor absoluto e é completamente insubistituível), diferentemente das coisas que apenas possuem valor relativo e que por isso possuem tão somente preço, ele pode se desenvolver e se aperfeiçoar em seus aspectos individuais, sociais, políticos e morais. Sendo assim, em parte o homem nasce homem, mas em outros apectos ele é formado pela educação. Ou seja, o homem é moldado pela educação na medida em que viabiliza o processo de passagem do estado de animalidade à civilidade, e, por sua vez, da civilidade à moralidade. Portanto, é nesse sentido que a educação forma $\mathrm{o}$ homem.
}

\begin{tabular}{|c|c|c|c|c|c|}
\hline intuitio & $\begin{array}{c}\text { ISSN } \\
1983-4012\end{array}$ & Porto Alegre & Vol.11 $-\mathrm{N}^{\circ} .2$ & $\begin{array}{c}\text { Dezembro } \\
2018\end{array}$ & p.66-86 \\
\hline
\end{tabular}


maioridade 5 em seus aspectos político e moral. Assim sendo, trata-se de compreender a relevância da teoria da educação kantiana para a formação da humanidade e do aperfeiçoamento moral, haja vista que o homem não nasce pronto, mas que precisa de cuidado $^{6}$ na infância, e meios que favoreçam o seu pleno desenvolvimento; que só é possível através da educação. Para esse fim, elegemos dois objetivos específicos. Primeiramente, pretendemos entender a teoria da educação de Immanuel Kant, considerando a respectiva divisão do autor (a educação física e a educação prática) e os conceitos que fundamentam sua teoria: cuidado, disciplina, instrução e direcionamento. E em seguida, buscaremos compreender como os princípios da pedagogia kantiana podem contribuir, de forma significativa, para a efetivação da maioridade e autonomia da razão; sobretudo em seu aspecto prático e moral.

Desse modo, a abordagem da temática proposta pelo presente artigo consiste na consciência de que o problema da educação foi e continua sendo de suma importância para formação do homem e da sociedade. E mais, a escolha da filosofia kantiana para fundamentar a investigação do problema aqui em questão se dá porque ele não apenas reconhece a problemática da educação como "o maior e o mais árduo problema que pode ser proposto aos homens"7, como também tem na boa educação a solução para o desenvolvimento moral do homem, como podemos perceber no seguinte trecho: "a natureza humana será sempre melhor desenvolvida e aprimorada pela educação, e que é possível chegar a dar àquela forma, a qual em verdade convém à humanidade" ${ }^{\prime}$. Ou seja, a teoria da educação de Kant é o alicerce que fundamenta a hipótese da presente investigação.

Destarte, a obra Über Pädagogik de Immanuel Kant será a principal fonte deste artigo, como já foi falado no início desta introdução. No entanto, além dessa obra, tomaremos como base da nossa investigação outras obras do filósofo prussiano, a fim de entendermos os conceitos necessários para a compreensão da sua teoria, como exemplo: Beantwortung der Frage: Was ist Aufklärung? (1784) ${ }^{9}$ e Idee zu einer allgemeinen Geschichte in weltbürgerlicher Absicht $(1784)^{10}$. E no que tange as fontes secundárias, utilizaremos algumas obras e artigos que dizem

\footnotetext{
${ }^{5}$ A maioridade é a capacidade de se servir de seu próprio entendimento sem que esteja sujeito a tutela de outrem.

${ }^{6}$ Cuidado diz respeito ao suprimento das necessidades tanto na conservação e quanto no trato.

${ }^{7}$ KANT, Immanuel. Sobre a pedagogia. Tradução Francisco C. Fontanella. Piracicaba: Editora Unimep, 1999, p. 20.

${ }^{8}$ KANT, Immanuel. Sobre a pedagogia. Tradução Francisco C. Fontanella. Piracicaba: Editora Unimep, 1999, p.16.

${ }^{9}$ Resposta à pergunta: o que é o Esclarecimento? Textos Seletos. Tradução Floriano de Sousa Fernandes. 3 ed. Rio de Janeiro: Editora Vozes, 2005.

${ }^{10}$ Ideia de uma História Universal com um propósito Cosmopolita. Tradução Artur Morão. Lusosofia: press, 2013.
}

\begin{tabular}{|c|c|c|c|c|c|}
\hline intuitio & $\begin{array}{c}\text { ISSN } \\
1983-4012\end{array}$ & Porto Alegre & Vol.11 - No.2 & $\begin{array}{c}\text { Dezembro } \\
2018\end{array}$ & p.66-86 \\
\hline
\end{tabular}


respeito à teoria da educação kantiana, como exemplo os textos dos seguintes autores: Bresolin, Carvalho, Oliveira, Rosa e La Taille.

\section{A teoria da educação kantiana}

O problema da educação é de suma importância para a formação humana, visto que, como afirma Kant, o homem é a única criatura que precisa de educação. Mas por que o homem é o único ser que carece de educação? Ora, Kant define o homem como um ser sensível, determinado pelas leis da natureza como os demais animais. Mas também o define como um ser racional (inteligível), que pode agir segundo as leis da liberdade. Ou seja, o homem não se reduz a determinação da sua natureza antropológica, mas pode ser algo além de todo determinismo porque tem livre-arbítro e escolha.

A título de exemplo, podemos fazer uma simples comparação entre o homem e a laranjeira: o homem se distingue da laranjeira. Ela, diferentemente do homem, está determinada a ser apenas uma única coisa, isto é, dar laranjas, e não pode ser nada além disso. A laranjeira não pode simplesmente escolher não dar laranjas, pois não tem a faculdade da razão para libertá-la do determinismo das leis naturais. Ou seja, o homem pode escolher, por exemplo, sua profissão, se casa ou não, se mente ou não, se rouba ou não, etc., devido a sua racionalidade. E neste âmbito, o homem pode ser algo além de todo determinismo natural, haja vista que o homem, na filosofia kantiana, é dualista, isto é, se dá no conflito entre as leis da natureza, que o determina a agir apenas segundo as suas necessidades naturais, e as leis da liberdade, que o permite ir além de todo determinismo e agir moralmente (que a mais pura forma de liberdade possível ao homem). E é justamente por possuir uma capacidade que o liberta do determinismo natural que a educação assume um papel de extrema importância, papel esse que só se aplica ao homem; contribuindo para o processo de compreensão das formulações dos princípios racionais que o permite conquistar a plena autonomia moral.

Nesse sentido, se a educação é única e exclusivamente necessária aos homens, ela é de algum modo algo que nos diferencia dos demais animais. E se assim é, podemos afirmar que a educação contribui para a aprendizagem do uso racional, e faz com que o homem em geral não aja apenas como os demais animais irracionais, que são determinados pelas leis da natureza. A educação permite que os homens aprendam a fazer uso da razão por meio da educação negativa, que objetiva eliminar a selvageria e animalidade, e por meio da educação positiva, que consiste

\begin{tabular}{|c|c|c|c|c|c|}
\hline intuitio & $\begin{array}{c}\text { ISSN } \\
1983-4012\end{array}$ & Porto Alegre & Vol.11 - No.2 & $\begin{array}{c}\text { Dezembro } \\
2018\end{array}$ & p.66-86 \\
\hline
\end{tabular}


no ensino de habilidades (o uso instrumental da razão), como veremos no decorrer desse artigo. Cabe-nos então investigar, primeiramente, como é possível garantir que o homem se torne verdadeiramente homem, para, em seguida, averiguar a possibilidade da educação contribuir no aperfeiçoamento, tanto do indivíduo, quanto da espécie humana em geral. Logo, é considerando o papel essencial que a educação tem na formação humana, e no desenvolvimento civil e moral, que pretendemos compreender, a princípio, a teoria da educação de Immanuel Kant.

A teoria da educação de Immanuel Kant ${ }^{11}$ se divide em duas partes: Sobre a educação física e Sobre a educação prática. Considerando assim a divisão proposta pelo próprio autor, decidimos também dividir a presente seção em duas partes: A educação física e $A$ educação prática. Na primeira, objetivamos compreender a parte física da sua pedagogia. E para esse fim, a subdividimos em duas subseções, ei-lhas: Da parte negativa: o cuidado e a disciplina e Da parte positiva: a instrução e o direcionamento. Na segunda parte, objetivamos entender a parte prática da pedagogia kantiana, visto que é, sobretudo, nessa parte que iremos encontrar os conceitos e argumentos necessários para defender uma teoria da educação com fins ao aperfeiçoamento da espécie humana.

\subsection{A educação física}

Kant divide a parte que contempla a educação física em duas partes: a parte negativa, denominada de cuidados $^{12}$ e disciplina ${ }^{13}$, e a parte positiva, denominada de instrução e direcionamento $^{14}$. Ele afirma que "a educação física consiste propriamente nos cuidados materiais prestados às crianças ou pelos pais, ou pelas amas de leite, ou pelas babás" 15 . Portanto, a fim de compreendermos o que é a educação física, em termos kantianos, e sua implicação na teoria da educação dele, neste tópico trataremos, mais especificamente, dos conceitos que fundamentam o conteúdo referente à educação física: cuidado, disciplina, instrução e direcionamento.

\footnotetext{
${ }^{11}$ Essa obra na verdade foi publicada por um aluno de Kant. No entanto o seu conteúdo diz respeito ao curso ministrado por Immanuel Kant na Universidade onde lecionava a disciplina de Pedagogia.

12 "Por cuidados entendem-se as preocupações que os pais tomam para impedir que as crianças façam uso nocivo de suas forças" (KANT, 1999, p. 11). Ou seja, refere-se a conservação e o trato. Segundo Kant o homem é o único animal que necessita de cuidados visto que os demais necessitam no máximo de nutrição.

13 "A disciplina transforma animalidade em humanidade" (KANT, 1999, p. 12). Ou seja, para Kant esse conceito puramente negativo "é o que impede ao homem de desviar-se do seu destino. De desviar-se da humanidade, através das suas inclinações animais" (KANT, 1999, p. 12).

14 "Direcionamento é a condução na prática daquilo que foi ensinado" (KANT, 1999, p. 30).

${ }^{15}$ KANT, Immanuel. Sobre a pedagogia. Tradução Francisco C. Fontanella. Piracicaba: Editora Unimep, 1999, p. 37.
}

\begin{tabular}{|c|c|l|l|c|c|}
\hline intuitio & $\begin{array}{c}\text { ISSN } \\
1983-4012\end{array}$ & Porto Alegre & Vol.11- $\mathrm{N}^{\circ} .2$ & $\begin{array}{c}\text { Dezembro } \\
2018\end{array}$ & p.66-86 \\
\hline
\end{tabular}




\subsubsection{Da parte negativa: o cuidado e a disciplina}

No que tange a parte negativa da educação cabe-nos perceber, de antemão, que para Kant: “a primeira educação deve ser puramente negativa, isto é, que nada cabe acrescentar às preocupações tomadas pela natureza, mas restringir-se a não perturbar a sua ação"16. Ou seja, "o primeiro passo toca à disciplina, e não ao ensinamento"17. Kant fundamenta, especificamente, a educação negativa em dois conceitos: cuidados e disciplina. O cuidado é a preocupação que os responsáveis devem ter com a conservação e o bem estar físico da criança. Ou seja, além da incumbência de prover com a alimentação, deve-se cuidar para que a criança não cometa ações que a deixe em perigo, enquanto que a disciplina é responsável por sujeitar o homem, desde a mais tenra infância, às leis da humanidade ${ }^{18}$ através da percepção da força dessas leis; que devem ter sua força e poder de coação pelo valor em si mesmo dessas leis e não por sua finalidade. Portanto, trata-se de uma coação externa (a discplina) que objetiva a internalização do princípio da coação da própria razão.

Segundo Kant, "Na educação, o homem deve, portanto: ser disciplinado. Disciplinar quer dizer: procurar impedir que a animalidade prejudique o caráter humano, tanto no indivíduo como na sociedade. Portanto, a disciplina consiste em domar a selvageria"19. Logo, podemos afirmar que a disciplina exerce papel essencial na pedagogia kantiana, considerando que ela tem a função de retirar do homem o seu estado de selvageria e de animalidade. Por conseguinte, ela é negativa, visto que o seu papel educacional é evitar que homem se desvie do seu destino: a perfeição humana; que só é possível com a plena autonomia da vontade ${ }^{20}$. No entanto, devemos entender que Kant defende uma disciplina com fins à liberdade e, por isso, a educação com fins ao aperfeiçoamento humano não deve ser escravizante e opressora, mas uma disciplina com fins à liberdade.

Ainda no que diz respeito à disciplina, Kant considera necessário que a criança seja submetida a ela desde cedo, visto que o homem, apesar de ser inclinado à liberdade, não sabe

${ }^{16}$ KANT, Immanuel. Sobre a pedagogia. Tradução Francisco C. Fontanella. Piracicaba: Editora Unimep, 1999, p.41 e 42.

${ }^{17}$ KANT, Immanuel. Sobre a pedagogia. Tradução Francisco C. Fontanella. Piracicaba: Editora Unimep, 1999 , p. 58.

18 As leis da humanidade consiste nos deveres para conosco e os deveres para com os demais seres humanos. Trataremos especificamente desses deveres na parte da educação prática.

${ }^{19}$ KANT, Immanuel. Sobre a pedagogia. Tradução Francisco C. Fontanella. Piracicaba: Editora Unimep, 1999 , p.25.

${ }^{20}$ A vontade torna-se autônoma quando o indivíduo a coloca sob a égide do mandamento da razão. Ou seja, quando a ação do sujeito se basea nas leis e imperativos formulados pela razão prática.

\begin{tabular}{|c|c|c|c|c|c|}
\hline intuitio & $\begin{array}{c}\text { ISSN } \\
1983-4012\end{array}$ & Porto Alegre & Vol.11- No.2 & $\begin{array}{c}\text { Dezembro } \\
2018\end{array}$ & p.66-86 \\
\hline
\end{tabular}


fazer bom uso dela, sendo, portanto, necessário aprender a usá-la bem. E mais, ele reforça que uma vez acostumado a gozar dessa rude liberdade, torna-se extremamente difícil desenvolver a humanidade no homem; que é seu verdadeiro destino. Em vista disso, podemos dizer que a teoria da educação de Kant reside na tensão entre a coação da disciplina e a liberdade. E é essa tensão que possibilita conquistar a autonomia da vontade e a plena perfeição humana. Mas, como isso é possível?

No que tange ao problema da tensão entre a disciplina e a liberdade, e também à possibilidade dessa tensão ser essencial para a conquista da verdadeira destinação do homem, La Taille afirma, em seu artigo A educação moral: Kant e Piaget, que essa tensão é problema chave para compreensão da teoria kantiana da educação. Partindo dessa interpretação, ele declara o seguinte: "Kant distingue duas linhas pedagógicas: a disciplina e a instrução. As duas vão desempenhar papel na educação moral. Porém, um problema se apresenta. A disciplina é coercitiva: como articulá-la com a liberdade e a autonomia da vontade, condições necessárias à moralidade?"21.

Em seguida, o professor La Taille continua respondendo com uma citação do próprio Kant:

Escreve Kant: "Um dos maiores problemas da educação é conciliar sob uma coação legítima à submissão e à faculdade de se servir de sua própria liberdade. Pois a coação é necessária! Mas, como cultivar a liberdade pela coação? É preciso que eu acostume meu aluno a usufruir da liberdade pela coação, e que, ao mesmo tempo, o instrua a fazer bom uso de sua liberdade. Sem isso, haveria nele apenas puro mecanismo; o homem privado de educação não sabe se servir de sua liberdade. E necessário que, desde cedo, sinta a resistência inevitável da sociedade, a fim de aprender a conhecer como é difícil bastar-se a si mesmo, suportar privações e adquirir o necessário para se tornar independente" (p. 46). Portanto, a coação é necessária: é o primeiro passo para se atingir a liberdade. ${ }^{22}$

Ou seja, a coação da disciplina é de suma importância para a teoria da educação kantiana, haja vista que sem ela o homem não é capaz de aprender a usar corretamente a liberdade sem fazer qualquer uso nociso a si mesmo e a pessoa do outro. Portanto, a discplina coercitiva, quando ministrada na primeira infância, é um mecanismo extremamente importante para o homem aprender a usar sua liberdade em sociedade (passagem da animalidade à civilidade), a fazer uso da liberdade sem ferir a liberdade alheia, por exemplo. Neste sentindo, ela é o primeiro

${ }^{21}$ LA TAILlE, Y. de. A educação moral: Kant e Piaget. In.: Macedo, L. de. (Org.) Cinco estudos de educação moral. São Paulo: Casa do Psicólogo, 1996, p.38.

${ }^{22}$ LA TAILlE, Y. de. A educação moral: Kant e Piaget. In.: Macedo, L. de. (Org.) Cinco estudos de educação moral. São Paulo: Casa do Psicólogo, 1996, p. 138 e 139).

\begin{tabular}{|c|c|l|l|c|c|}
\hline intuitio & $\begin{array}{c}\text { ISSN } \\
1983-4012\end{array}$ & Porto Alegre & Vol.11- $\mathrm{N}^{\circ} .2$ & $\begin{array}{c}\text { Dezembro } \\
2018\end{array}$ & p.66-86 \\
\hline
\end{tabular}


passo em busca da liberdade e, consequentemente, a autonomia moral. O conceito de liberdade, por sua vez, é o segredo para compreensão da teoria da educação kantiana, à medida que ela é o fundamento da moralidade. Logo, a liberdade é o que possibilita ao homem se desvincular do determinismo das leis da natureza e agir moralmente. Dessa maneira, devemos considerar que "não é suficiente treinar as crianças; urge que aprendam a pensar. Devem-se observar os princípios dos quais todas ações derivam" ${ }^{23}$. Nesse sentido, a educação kantiana se coloca como uma educação libertadora, que não objetiva fazer as crianças reproduzirem uma ideia préfabricada, mas sim dar condições delas aprenderem a pensar por si mesmas.

La Taille ressalta ainda a importância que a educação tem no desenvolvimento do futuro da humanidade na teoria kantiana. Como podemos perceber no seguinte trecho: "E, portanto, no seio da educação que se disputa o futuro da humanidade, pois ela, a educação, é fonte de todos os bens do mundo, contanto que seja levada a sério e dirigida para um ideal de perfeição humana"24. Por conseguinte, o ideal de perfeição humana é o objetivo último de toda teoria da educação que almeja os bens da humanidade, considerando que, como afirma Kant, "A ideia de uma educação que desenvolva no homem todas as suas disposições naturais é verdadeira absolutamente" 25 . Isto é, uma educação que desenvolva suas qualidades humanas e permita chegar a sua verdadeira destinação, que é, a humanidade em seu estado de perfeição. ${ }^{26}$

Nesse contexto, podemos perceber que o grande problema que a teoria da educação kantiana coloca é o seguinte: como conciliar o exercício da liberdade com a submissão da disciplina, do constrangimento? Kant dá a seguinte resposta para essa questão: "É preciso provar que o constrangimento, que lhe é imposto, tem por finalidade ensinar a usar bem da sua liberdade, que a educamos para que possa ser livre um dia, isto é, dispensar os cuidados de outrem"27. Sendo assim, o objetivo de Kant não é reprimir a liberdade, impedindo que o homem seja autônomo, mas tão somente prepará-lo para exercer sua liberdade de forma autônoma e moral. ${ }^{28}$

\footnotetext{
${ }^{23}$ KANT, Immanuel. Sobre a pedagogia. Tradução Francisco C. Fontanella. Piracicaba: Editora Unimep, 1999, p.27.

${ }^{24}$ LA TAILlE, Y. de. A educação moral: Kant e Piaget. In.: Macedo, L. de. (Org.) Cinco estudos de educação moral. São Paulo: Casa do Psicólogo, 1996, p.136.

${ }^{25}$ KANT, Immanuel. Sobre a pedagogia. Tradução Francisco C. Fontanella. Piracicaba: Editora Unimep, 1999, p.17.

${ }^{26}$ Kant considera que a perfeição humana é a verdadeira disposição natural do homem, ou seja, a finalidade de sua existência. Cabe-nos aqui saber os meios que a educação fornece para a conquista dessa finalidade.

${ }^{27}$ KANT, Immanuel. Sobre a pedagogia. Tradução Francisco C. Fontanella. Piracicaba: Editora Unimep, 1999, p. 33 e 34 .

${ }^{28}$ A passagem da heteronomia da disciplina (coação externa) para a autonomia (coação interna) se dá pela educação. Primeiramente, a criança é submetida a coação externa para entender como deve usar a sua liberdade sem ferir a
}

\begin{tabular}{|c|c|c|c|c|c|}
\hline intuitio & $\begin{array}{c}\text { ISSN } \\
1983-4012\end{array}$ & Porto Alegre & Vol.11 - No.2 & $\begin{array}{c}\text { Dezembro } \\
2018\end{array}$ & p.66-86 \\
\hline
\end{tabular}




\subsubsection{Da parte positiva: a instrução e o direcionamento}

Além da parte negativa da educação, a pedagogia kantiana consiste em uma parte positiva. Ou seja, uma parte da educação que não pretende evitar ou retirar algo danoso para a formação humana, mas sim agregar habilidades e aprendizagens necessárias para a realização da inteira destinação humana, qual seja, à perfeição humana. Sendo assim, "a parte positiva da educação física é a cultura. Por ela o homem se distingue do animal. A cultura consiste notadamente no exercício das forças da índole" ${ }^{\text {"2 }}$ e se fundamenta, sobretudo, nos conceitos de instrução ou escolástica e direcionamento. E é justamente a cultura que possibilita, propriamente, a distinção entre o homem e os demais animais. Quer dizer, a cultura é responsável pela construção do caráter, do temperamento e da índole do homem, desde o seu nascimento até a sua morte.

Kant divide ainda a cultura em: cultura do corpo e cultura da alma. No que tange à cultura do corpo, Kant ressalta a necessidade de que ela esteja de acordo com as normas sociais, e por essa razão, até os brinquedos e as brincadeiras infantis devem ser fixadas segundo essas normas sociais e com fins ao aperfeiçoamento humano. Kant, ao tratar dessa questão, dá o exemplo do balanço que objetiva fortalecer o corpo. Além do balanço ele ressalta a importância de outras brincadeiras, como podemos perceber pela seguinte citação: "a brincadeira da cabracega, por exemplo, é para saber como poderiam desempenhar-se, caso fossem privadas de um sentido. O pião é um jogo admirável. Esse tipo de brincadeira infantil dá aos homens ocasiões para reflexões ulteriores e, às vezes, são ocasiões de importantes descobertas" ${ }^{" 30}$. Além de todos esses benefícios a brincadeira tem o objetivo de fazer com que as crianças dediquem um certo tempo e concentração a tais atividades previamente delimitas e benéficas, em detrimento de outras sem finalidade, proporcionando assim a disciplina.

Já no que diz respeito a cultura da alma, Kant ressalta que não devemos confundi-la com a educação moral, visto que, assim como a cultura do corpo pertence a parte física da pedagogia, assim também a cultura da alma pertence à formação física. À vista disso, podemos afirmar que a

liberdade do outro. No decorrer do processo de desevolvimento o homem tem a oportunidade de agir sem a tutela alheia, isto é, heteronomia e passar a fundamentar suas ações na autonomia da vontade (a verdadeira liberdade), pois apenas quando o homem for autônomo será verdadeiramente livre e não precisará mais ser submetido a disciplina (que se trata apenas da educação negativa e que é reservada às crianças).

${ }^{29}$ KANT, Immanuel. Sobre a pedagogia. Tradução Francisco C. Fontanella. Piracicaba: Editora Unimep, 1999, p.53.

${ }^{30}$ KANT, Immanuel. Sobre a pedagogia. Tradução Francisco C. Fontanella. Piracicaba: Editora Unimep, 1999, p.56.

\begin{tabular}{|c|c|l|l|l|l|}
\hline intuitio & $\begin{array}{c}\text { ISSN } \\
1983-4012\end{array}$ & Porto Alegre & Vol.11- №.2 & $\begin{array}{c}\text { Dezembro } \\
2018\end{array}$ & p.66-86 \\
\hline
\end{tabular}


cultura da alma não garante a formação moral, mas tão somente o uso instrumental da razão ${ }^{31}$. É por haver essa distinção que afirma Kant: "Um homem pode ter uma sólida formação física, pode ter um espírito muito bem formado e ser, dum homem moralmente formado e ser, desse modo, uma criatura má" ${ }^{32}$. Sendo assim, tanto a parte da cultura do corpo quanto da cultura da alma não dizem respeito à moral, mas tão somente à formação cultural.

No que tange ainda à cultura física, seja ela do corpo ou da alma, Kant faz a seguinte divisão: cultura livre e cultura escolática. A primeira se refere ao divertimento, enquanto que a segunda diz respeito à obrigação. Neste sentido, podemos dizer que a teoria da educação kantiana não apenas valoriza que a criança desfrute do ócio, do divertimento e das brincadeiras com finalidades culturais, mas também que ela se submeta a obrigação do trabalho, para que aprenda a superar a preguiça e que compreenda a importância do trabalho para o homem e para a sociedade. E é justamente na cultura da obrigação que entra a escola e o seu papel na educação das crianças, considerando que é na escola que a criança aprende a importância do trabalho e quando ficar adulto pode entender a necessidade de obter o seu próprio sustento, além de ser na escola que a criança aprende as habilidades necessárias para o uso instrumental da razão. Mas devemos tomar cuidado para a educação ser impositiva e não escravizante. Isto é, o seu papel deve ser desenvolver o esclarecimento e o aperfeiçoamento da natureza humana, e não o adestramento e a submissão irracional a outrem.

\subsection{Educação prática}

Immanuel Kant subdivide a parte que contempla a educação prática em três. Ei-las: a cultura escolástica ou mecânica, a formação pragmática e a cultura moral. A primeira, diz respeito à habilidade ${ }^{33}$, a segunda, consiste na prudência $^{34}$ e, por fim, a terceira, trata-se da moralidade ${ }^{35}$.

\footnotetext{
${ }^{31}$ Trataremos, mais especificamente, da razão instrumental no terceiro capítulo deste trabalho: Da educação ao ideal de humanidade.

${ }^{32}$ KANT, Immanuel. Sobre a pedagogia. Tradução Francisco C. Fontanella. Piracicaba: Editora Unimep, 1999, p.59.

${ }^{33}$ Para Kant habilidade consiste em um conhecimento sólido, ou seja, um conhecimento que se traduz em ações. E que na pedagogia kantiana, esse conceito, é essencial para a formação do caráter, pois a "habilidade é necessária ao talento" (KANT, 1999, p.85).

34 "A prudência consiste na arte de aplicar aos homens a nossa habilidade, ou seja, de nos servir dos demais para os nossos objetivos" (KANT, 1999, p.85, grifo do autor). "Ora a destreza na escolha dos meios para atingir o maior bem-estar próprio pode-se chamar prudência [Klugheit] $(*)$ no sentido mais restrito da palavra." (KANT, 2011, p. 54 e 55). Immanuel Kant atribui a essa qualidade como a responsável por moderar as paixões. E mais, ele diz que "a prudência mundana concerne ao temperamento" (KANT, 1999, p. 85).

35 "A moralidade diz respeito ao caráter" (KANT, 1999, p. 85, grifo do autor).
}

\begin{tabular}{|c|c|l|l|c|c|}
\hline intuitio & $\begin{array}{c}\text { ISSN } \\
1983-4012\end{array}$ & Porto Alegre & Vol.11- $\mathrm{N}^{\circ} .2$ & $\begin{array}{c}\text { Dezembro } \\
2018\end{array}$ & p.66-86 \\
\hline
\end{tabular}




\subsubsection{A cultura escolástica, pragmática e moral}

A cultura escolástica ou mecânica consiste em desenvolver a habilidade. Ela é a primeira fase da educação prática, visto que, para desenvolver a prudência, que é a segunda parte da educação prática, o homem necessita primeiramente desenvolver a habilidade. Portanto, a grande importância dessa formação se dá na valoração do homem em si mesmo, visto que a habilidade é a essência do caráter $^{36}$ do homem. Como afirma Kant:

No que toca à habilidade, requer-se que seja sólida e não passageira. Não se deve mostrar ares de quem conhece algo que não se possa depois traduzir em ações. A habilidade deve, antes de mais nada, ser bem fundada e torna-se pouco a pouco um hábito do pensar. É o elemento essencial do caráter de um homem. A habilidade é necessária ao talento. ${ }^{37}$

No que tange a prudência, Kant afirma que ela é a "arte de aplicar aos homens a nossa habilidade, ou seja, de nos servir dos demais para os nossos objetivos" ${ }^{38}$. Essa prudência, na qual o homem deve aprender, por exemplo, a dissimular, é chamada de prudência mundana e ela tem a sua importância porque permite ao homem alcançar um determinado objetivo em sociedade. A prudência mundana diz respeito ao temperamento ${ }^{39}$, e tem por finalidade ajudar a moderar as paixões. Concerne ao temperamento, por exemplo, a simpatia. Kant, no entanto, reforça que muito embora a simpatia deva ser cultivada, não se deve permitir que a criança sucumba ao sentimentalismo da compaixão nostálgica, considerando que ela é um mal ao caráter e não tem nenhuma utilidade prática; servindo apenas para lamentação. Nesse sentido, podemos perceber que Kant considera as paixões como algo ruim para a formação do caráter do homem e, portanto, deve ser evitada.

Podemos afirmar que o cultivo do caráter e o desenvolvimento da prudência não são propriamente a ação moral, mas unicamente, a aparência moral permitida, isto é, o estado de

\footnotetext{
${ }^{36}$ O caráter é a "constituição particular" (KANT, 2011, p. 22) de cada homem e que possibilita fazer uso dos dons naturais.

${ }^{37}$ KANT, Immanuel. Sobre a pedagogia. Tradução Francisco C. Fontanella. Piracicaba: Editora Unimep, 1999, p. 85.

${ }^{38}$ KANT, Immanuel. Sobre a pedagogia. Tradução Francisco C. Fontanella. Piracicaba: Editora Unimep, 1999, 85

39 "Do ponto de vista fisiológico, quando se fala de temperamento entende-se a constituição corporal (a estrutura forte ou fraca) e a compleição (os fluídos, aquilo que no corpo se move regulado pela força vital, onde também se incluem o calor ou o frio na elaboração desses humanos). Mas, sob o aspecto psicológico, isto é, como temperamento da alma (da faculdade de sentir e de desejar), essas expressões, tomadas de empréstimo à constituição sanguínea, são representadas somente conforme a analogia do jogo dos sentimentos e desejos com as causas motrizes corporais (dentre as quais o sangue é a principal)" (KANT, 2006, p. 182).
}

\begin{tabular}{|c|c|l|l|c|c|}
\hline intuitio & $\begin{array}{c}\text { ISSN } \\
1983-4012\end{array}$ & Porto Alegre & Vol.11- $\mathrm{N}^{\circ} .2$ & $\begin{array}{c}\text { Dezembro } \\
2018\end{array}$ & p.66-86 \\
\hline
\end{tabular}


civilidade enquanto o ser moral não alcança seu estado de perfeição. Por essa razão, Kant afirma, na Anthropologie in pragmatischer hinsicht, que:

Feito as contas, quanto mais os seres humanos se tornam civilizados, tanto maior é o número de atores; eles aparentam simpatia, respeito pelos outros, recato, altruísmo, sem enganar ninguém com isso, porque cada um dos demais está de acordo que não se está sendo exatamente sincero, e também é muito bom que as coisas sejam assim no mundo. Pois, porque os homens representam esse papel, as virtudes, cuja aparência apenas afetam por um longo espaço de tempo, são por fim pouco a pouco realmente despertadas e passam a fazer parte do caráter. ${ }^{40}$

Logo, o desenvolvimento da civilidade e, consequentemente, o caráter são essenciais para a vida coletiva, para a realização do interesse da sociedade no mundo fenomênico provisoriamente. Ou seja, enquanto a ideia de perfeição humana não é efetivada no mundo fenomênico. Neste sentido, devemos compreender que a civilidade e a "prudência mundana" é, simplesmente, uma etapa anterior à moralidade, visto que a moralidade é, propriamente, aquilo que se refere ao caráter moral e para desenvolvê-la nas crianças é necessário "ensinar-lhe, da melhor maneira, através de exemplos e com regras, os deveres a cumprir" ${ }^{41}$. Ei-lhos: os deveres para consigo mesmas e os deveres para com os demais.

Os deveres para consigo mesmo equivale, por exemplo, a buscar se vestir e comer de modo conveniente, ser comedido, sóbrio e moderado. Quer dizer, deve-se evitar seguir seus desejos e inclinações, haja vista que, é dever para consigo mesmo respeitar a sua própria dignidade inteiror, conservar a dignidade da natureza humana em sua própria pessoa. Por isso, diz Kant a respeito dos deveres para consigo mesmo: "é seu dever não renegar em sua própria pessoa essa dignidade da natureza humana" ${ }^{42}$. Portanto, cabe a educação a responsabilidade de ensinar a criança a compreender a importância da dignidade da pessoa humana em sua própria pessoa e de ensiná-la a não inferiorizar a sua própria pessoa; se humilhando abaixo de qualquer animal. À guisa de exemplo de inferiorização temos: contar uma mentira, pois a mentira é desprezível e desqualifica a dignidade humana.

${ }^{40}$ KANT, Immanuel. Antropologia de um ponto de vista pragmático. Tradução: Clélia Aparecida Martins. São Paulo: Iluminuras, 2006, p. 50).

${ }^{41}$ KANT, Immanuel. Sobre a pedagogia. Tradução Francisco C. Fontanella. Piracicaba: Editora Unimep, 1999, p.89.

${ }^{42}$ KANT, Immanuel. Sobre a pedagogia. Tradução Francisco C. Fontanella. Piracicaba: Editora Unimep, 1999, p. 89.

\begin{tabular}{|c|c|c|c|c|c|}
\hline intuitio & $\begin{array}{c}\text { ISSN } \\
1983-4012\end{array}$ & Porto Alegre & Vol.11- No.2 & $\begin{array}{c}\text { Dezembro } \\
2018\end{array}$ & p.66-86 \\
\hline
\end{tabular}


Os deveres para com os demais, também, são de extrema importância, pois é por meio deles que as crianças aprendem a respeitar e dar atenção aos direitos humanos e, mais eminentemente ainda, colocá-los em prática com frequência. Na Anthropologie in pragmatischer hinsicht, Kant chega a seguinte conclusão:

O resultado final da antropologia pragmática em relação à destinação do ser humano e à característica de seu aprimoramento consiste no seguinte. O ser humano está destinado, por sua razão, a estar numa sociedade com seres humanos e a se cultivar, civilizar e moralizar nela por meio das artes e das ciências, e por maior que possa ser sua propensão animal a se abandonar passivamente aos atrativos da comodidade e do bemestar, que ele denomina felicidade, ele está destinado a se tornar ativamente digno da humanidade na luta com os obstáculos que a rudeza coloca para ele. ${ }^{43}$

No entanto, no que tange a concretização da interira destinação humana, qual seja, a perfeição da natureza humana, Kant alerta para uma grande dificuldade que deve ser superada: "O ser humano tem, pois, de ser educado para o bem, mas aquele que deve educá-lo é novamente um ser humano que ainda se encontra em meio à rudeza da natureza e deve realizar aquilo de que ele mesmo necessita. Daí o constante desvio de sua destinação e os retornos repetidos a ela"44. Por isso que, Kant reafirma a importância de não educarmos as crianças segundo os interesses da sociedade presente, mas sobretudo, colocar o ideal de perfeição humana como o princípio norteador da educação com fins ao esclarecimento. Ou seja, cabe, tão somente, a educação consolidar a suprema etapa da pedagogia que "é a consolidação do caráter"45. E, continua Kant, com a seguinte definição de caráter: “consiste na resolução firme de querer fazer algo e colocá-lo realmente em prática" ${ }^{46} \operatorname{Logo}$, uma pessoa realmente moralizada tem a força de agir não apenas segundo as suas inclinações e paixões, isto é, segundo as leis da natureza que nos determina, mas segundo as leis da liberdade que nos permite superar nossas limitações naturais por meio da razão prática, o imperativo categórico.

\footnotetext{
${ }^{43}$ KANT, Immanuel. Antropologia de um ponto de vista pragmático. Tradução: Clélia Aparecida Martins. São Paulo: Iluminuras, 2006, p. 219).

${ }^{44}$ Antropologia de um ponto de vista pragmático. Tradução: Clélia Aparecida Martins. São Paulo: Iluminuras, 2006, p. 219.

${ }^{45}$ KANT, Immanuel. Sobre a pedagogia. Tradução Francisco C. Fontanella. Piracicaba: Editora Unimep, $1999,87$.

${ }^{46}$ KANT, Immanuel. Sobre a pedagogia. Tradução Francisco C. Fontanella. Piracicaba: Editora Unimep, 1999 , p.87.
}

\begin{tabular}{|c|c|c|c|c|c|}
\hline intuitio & $\begin{array}{c}\text { ISSN } \\
1983-4012\end{array}$ & Porto Alegre & Vol.11 - No.2 & $\begin{array}{c}\text { Dezembro } \\
2018\end{array}$ & p.66-86 \\
\hline
\end{tabular}




\section{A pedagogia do esclarecimento}

Immanuel Kant, filósofo Iluminista, reconhece que o século XVIII, mesmo sendo um período caracterizado pela civilidade, cultura e disciplina, ainda não tinha alcançado o pleno esclarecimento e autonomia moral, como podemos conferir no seguinte trecho da obra Ideia de uma História Universal com um propósito Cosmopolita: "Estamos cultivados em alto grau pela arte e pela ciência. Somos civilizados, até ao excesso, em toda a classe de maneiras e na respeitabilidade sociais. Mas falta ainda muito para nos considerarmos já moralizados" 47 . Ou ainda, como afirma na obra Über Pädagogik: "Vivemos em uma época de disciplina, de cultura e de civilização, mas ela ainda não é a verdadeira moralidade" ${ }^{48}$. Apesar dessa consciência, Kant continuava cheio de esperança no progresso da humanidade. Ele acreditava que:

A educação é uma arte, cuja a prática necessita ser aperfeiçoada por várias gerações. Cada geração, de posse dos conhecimentos das gerações precedentes, está sempre melhor aparelhada para exercer uma educação que desenvolva todas as disposições naturais na justa proporção e de conformidade com a finalidade daquelas e, assim, guie toda humana espécie a seu destino. ${ }^{49}$

Neste contexto, o propósito de toda educação esclarecida deve ser pautado no ideal de perfeição humana, isto é, uma educação com fins ao aperfeiçoamento moral e o pleno esclarecimento da espécie humana. Isto posto, a educação deve ser dada as crianças de maneira tal que as dê condições de superar a preguiça, a covardia, as inclinações, os vícios e, sobretudo, ousar saber; de buscar a liberdade de pensamento enquanto ser moral. Mas, para que isso seja viável, devemos considerar a educação não como um problema concernente ao indivíduo particular, mas enquanto espécie humana, tendo em vista que a teoria kantiana objetiva o fim último do homem enquanto humanidade.

Considerando isso, Bresolin diz o seguinte a respeito da teoria da educação kantiana:

A educação kantiana, assim como toda sua obra, assenta-se sobre uma imagem crítica do homem, quer dizer, sobre a necessidade de uma perfeição a ser realizada. A educação compreende também a passagem da natureza à liberdade, pois, sem uma educação que

\footnotetext{
${ }^{47}$ KANT, Immanuel. Ideia de uma História Universal com um propósito Cosmopolita. Tradução: Artur Morão. Lusosofia: press, 2013, p.14.

${ }^{48}$ KANT, Immanuel. Sobre a pedagogia. Tradução Francisco C. Fontanella. Piracicaba: Editora Unimep, 1999, p. 28.

${ }^{49}$ KANT, Immanuel. Sobre a pedagogia. Tradução Francisco C. Fontanella. Piracicaba: Editora Unimep, 1999, p.
}

\begin{tabular}{|c|c|l|l|c|c|}
\hline intuitio & $\begin{array}{c}\text { ISSN } \\
1983-4012\end{array}$ & Porto Alegre & Vol.11- $\mathrm{N}^{\circ} .2$ & $\begin{array}{c}\text { Dezembro } \\
2018\end{array}$ & p.66-86 \\
\hline
\end{tabular}


vise à maioridade, é impossível pensar que o ideal de liberdade aproxime-se da efetividade. $\mathrm{O}$ homem tem necessidade de sua razão porque ela o torna o que ele realmente é: um ser racional. ${ }^{50}$

Sendo assim, com fins a compreendermos como os princípios da pedagogia kantiana podem contribuir, de forma significativa, para a efetivação da maioridade e autonomia da razão, dividimos este capítulo em duas seções: A maioridade e a autonomia e A pedagogia kantiana e a responsabilidade individual. A primeira seção trata acerca da relação entre a pedagogia kantiana e os conceitos de maioridade, autonomia e liberdade. A segunda seção ocupa-se da relação entre a pegadogia e a responsabilidade individual. Para esse fim, nos fundamentaremos, sobretudo, na obra Beantwortung der Frage: Was ist Aufklärung?

\subsection{A maioridade, a autonomia e a liberdade}

Na obra Beantwortung der Frage: Was ist Aufklärung? Kant define o conceito de maioridade como a capacidade de se servir do seu próprio entendimento sem depender da tutela de uma outra pessoa. A conquista da maioridade, por sua vez, é fundamental para se tornar uma pessoa esclarecida. Por essa razão que iniciamos o presente capítulo com a seguinte frase: "Sapere aude! Tenha a coragem de te servir de teu próprio entendimento, tal é portanto a divisa do Esclarecimento" ${ }^{51}$.

Além do conceito de maioridade, o conceito de autonomia também está ligado à conquista do esclarecimento, considerando que a autonomia é essencial para se obter a capacidade de servir-se do seu próprio entendimento sem depender de outrem, pois se a vontade do homem não for autonoma, torna-se impossível não se subemeter à tutela de outra pessoa. Ou seja, o conceito de autonomia é a capacidade de colocar leis para si mesmo, segundo a razão prática. E, portanto, uma vontade autonoma ${ }^{52}$ é a unica forma de alcançar o esclarecimento. $\mathrm{Na}$ verdade, o conceito de autonomia é o cerne da filosofia kantiana, visto que, para Kant, o homem só é completamente homem quando assume autonomamente todos os âmbitos de sua vida. A

\footnotetext{
50 BRESOLIN, Keberson. A filosofia da educação de Immanuel Kant: da disciplina à moralidade. Rio Grande do Sul: Educs, 2016, p. 57).

${ }^{51}$ KANT, Immanuel. Resposta à pergunta: o que é o Esclarecimento? Textos Seletos. Tradução: Floriano de Sousa Fernandes. 3 ed. Rio de Janeiro: Editora Vozes, 2005, p.1.

52 “Autonomia da vontade é aquela sua propriedade graças à qual ela é para si mesma a sua lei (independentemente da natureza dos objetos do querer). O princípio da autonomia é portanto: não escolher senão de modo a que as máximas da escolha estejam incluídas simultaneamente, no querer mesmo, como lei universal” (KANT, 2011, p. 90).
}

\begin{tabular}{|c|c|c|c|c|c|}
\hline intuitio & $\begin{array}{c}\text { ISSN } \\
1983-4012\end{array}$ & Porto Alegre & Vol.11- No.2 & $\begin{array}{c}\text { Dezembro } \\
2018\end{array}$ & p.66-86 \\
\hline
\end{tabular}


"autonomia é pois o fundamento da dignidade da natureza humana e de toda a natureza racional" 53 .

Além dos conceitos de maioridade e autonomia, temos o conceito de liberdade, que também é fundamental para o esclarecimento, visto que uma vontade só é autonoma se ela for livre das inclinações e paixões, isto é, das leis da natureza. De outro modo, apenas uma vontade realmente livre é autonoma, pois sem liberdade a vontade está submetida as leis da natureza e, portanto, exclui do homem qualquer chance de escolher para si leis que não sejam determinadas pela própria natureza. Logo, podemos concluir essa seção com a seguinte compreensão: os conceitos de maioridade, autonomia e liberdade são essenciais para a conquista do aperfeiçoamento humano, e que é impossível conquistar essa prefeição sem que esses três conceitos estejam presentes.

\subsection{A pedagogia kantiana e a responsabilidade individual}

Kant defende que a educação é essencial para a formação do homem, pois ela contribui para o aperfeiçoamento moral do gênero humano. No entanto, ele não rejeita a importância individual de cada um buscar a autonomia e o seu próprio esclarecimento, como podemos perceber pela seguinte citação: "Esclarecimento (Aufklärung) significa a saída do homem de sua minoridade, pela qual ele próprio é responsável. A minoridade é a incapacidade de se servir de seu próprio entendimento sem a tutela de um outro" 54 . Ou seja, embora cada um de nós necessite de cuidados e nos servir da tutela alheia, enquanto crianças, também precisamos da ousadia para crescermos, nos esclarecermos, nos tornarmos definitivamente um ser humano autônomo, maior, moral, livre e esclarecido.

Neste contexto, devemos ressaltar que a pedagogia pensada por Kant favorece esse processo de esclarecimento, pois ele não planejou uma educação com fins à servidão, mas sim, à autonomia. Portanto, a pegagogia kantiana é uma pedagogia do esclarecimento e da autonomia, considerando que ela se opõe a qualquer educação que reprima o crescimento e a liberdade humana, como é possivel perceber pela seguinte citação:

Após ter começado a emburrecer seus animais domésticos e cuidadosamente impedir que essas criaturas tranqüilas sejam autorizadas a arriscar o menor passo sem o andador

\footnotetext{
${ }^{53}$ KANT. Immanuel. Fundamentação da metafísica dos costumes. Lisboa: Edições 70, 2011, p.79.

${ }^{54}$ KANT, Immanuel. Resposta à pergunta: o que é o Esclarecimento? Textos Seletos. Tradução: Floriano de Sousa Fernandes. 3 ed. Rio de Janeiro: Editora Vozes, 2005, p.1.
}

\begin{tabular}{|c|c|c|c|c|c|}
\hline intuitio & $\begin{array}{c}\text { ISSN } \\
1983-4012\end{array}$ & Porto Alegre & Vol.11- No.2 & $\begin{array}{c}\text { Dezembro } \\
2018\end{array}$ & p.66-86 \\
\hline
\end{tabular}


que as sustenta, mostram-lhes em seguida o perigo que as ameaça se tentam andar sozinhas. Ora, esse perigo não é tão grande assim, pois após algumas quedas elas acabariam aprendendo a andar; mas um exemplo desse tipo intimida e dissuade usualmente toda tentativa ulterior. ${ }^{55}$

Em outras palavras, muito embora Kant ressalte a necessidade de cada um buscar libertarse da tutela alheia, de buscar se esclarecer, ele considera extremamente difícil tal tarefa, se formos educados de modo tal que a servidão passe a ser nossa segunda natureza, se formos educados para a servidão e não para a liberdade. Por essa razão, Kant condena a educação exclusivamente mecânica, sem liberdade de pensamento e sem a possibilidade de desenvolver o senso crítico, como observamos no seguinte trecho:

Preceitos e fórmulas, esses instrumentos mecânicos destinados ao uso racional, ou antes ao mau uso de seus dons naturais, são os entraves desses estado de minoridade que se perpetua. Quem o rejeitasse, no entanto, não efetuaria mais do que um salto incerto por cima do fosso mais estreito que seja, pois ele não tem o hábito de uma tal liberdade de movimento. Assim, são poucos os que conseguiram, pelo exercitar de seu próprio espírito, libertar-se dessa minoridade tendo ao mesmo tempo um andar seguro. ${ }^{56}$

Esse tipo de educação, segundo Kant, não está voltado para o ideal de perfeição humana e, por conseguinte, não ajuda o homem a se libertar da tutela e dos cuidados infatins da menoridade. Levando em consideração que o homem "precisa formar por si mesmo o projeto de sua conduta"57, a educação não pode ser o entrave para o destino da humanidade. Consequentemente, cabe à educação colaborar para a marcha do aperfeiçoamento humano, visto que só a educação pode contribuir para que não apenas um indivíduo isolado conquiste a sua inteira destinação, mas como também toda a espécie humana.

$\mathrm{Na}$ Anthropologie in pragmatischer hinsicht, Kant reforça esse pensamento no qual consagra o aperfeiçoamento humano à espécie humana e não a um indivíduo em particular. Segue o seguinte trecho que corrabora com essa afirmativa:

Pelo que cada homem teria de viver um tempo incomensuravelmente longo para aprender como deveria usar com perfeição todas as suas disposições naturais; ou, se a

\footnotetext{
${ }^{55}$ KANT, Immanuel. Resposta à pergunta: o que é o Esclarecimento? Textos Seletos. Tradução: Floriano de Sousa Fernandes. 3 ed. Rio de Janeiro: Editora Vozes, 2005, p. 02).

${ }^{56}$ KANT, Immannuel. Resposta à pergunta: o que é o Esclarecimento? Textos Seletos. Tradução: Floriano de Sousa Fernandes. 3 ed. Rio de Janeiro: Editora Vozes, 2005, p. 01).

${ }^{57}$ KANT, Immanuel. Sobre a pedagogia. Tradução Francisco C. Fontanella. Piracicaba: Editora Unimep, 1999, p.12.
}

\begin{tabular}{|c|c|l|l|c|c|}
\hline intuitio & $\begin{array}{c}\text { ISSN } \\
1983-4012\end{array}$ & Porto Alegre & Vol.11- $\mathrm{N}^{\mathrm{o} .2}$ & $\begin{array}{c}\text { Dezembro } \\
2018\end{array}$ & p.66-86 \\
\hline
\end{tabular}


natureza estabeleceu apenas um breve prazo à sua vida (como realmente acontece), ela necessita de uma série talvez incontável de gerações, das quais uma transmite à outra os seus conhecimentos, para que finalmente o seu germe, ínsito na nossa espécie, alcance o estádio de desenvolvimento que é de todo adequado à sua intenção. E esse momento, pelo menos na ideia do homem, será a meta dos seus esforços porque, de outro modo, as disposições naturais deveriam, na sua maior parte, ter-se por inúteis e sem finalidade - o que eliminaria todos os princípios práticos e, assim, a natureza, cuja sabedoria servirá de princípio para julgar todas as restantes coisas, só no homem se tornaria suspeita de um jogo infantil. ${ }^{58}$

Sendo assim, a educação não deve favorecer o aprisionamento, mas sim a liberdade e a autonomia, pois, do contrário, pode impedir não apenas o crescimento individual, mas de toda espécie humana. Observando esse problema, Kant critica o modelo educacional escravizante, pois a sua consequência é desastroza para toda humanidade, visto que "é portanto difícil para todo homem tomado individualmente livrar-se dessa minoridade que se tornou uma espécie de segunda natureza. Ele se apegou a ela, e é então realmente incapaz de se servir de seu entendimento, pois não deixam que ele o experimente jamais"59.

Tendo em vista a importância da educação para a formação humana e para a efetivação do seu destino, Kant elabora uma pedagogia com fins à autonomia e ao esclarecimento, uma pedagogia com fins à liberdade; que se opõe a qualquer modelo de educação que não tenha o ideal de humanidade como finalidade. No entanto, cabe levarmos em conta que Kant não defende a tese de que a educação é a garantia da perfeição humana, dado que para ele apenas a razão prática torna isso possível. Aliás, devemos compreender que, para Kant, a perfeição humana se dá, tão somente, na efetivação moral. ${ }^{60}$

Neste contexto, a educação não transforma a humanidade em seres autonomos, esclarecidos e morais, mas unicamente ajuda na dura tarefa do homem fazer uso da sua capacidade racional de modo correto; ensinando a fazer uso do imperativo hipotético, isto é, no "caso de a acção ser apenas boa como meio para qualquer outra coisa"61. Mas, a perfeição

\footnotetext{
${ }^{58}$ KANT, Immanuel. Ideia de uma História Universal com um propósito Cosmopolita. Tradução: Artur Morão. Lusosofia: press, 2013, p. 5 e 6.

${ }^{59}$ KANT, Immanuel. Resposta à pergunta: o que é o Esclarecimento? Textos Seletos. Tradução: Floriano de Sousa Fernandes. 3 ed. Rio de Janeiro: Editora Vozes, 2005, p. 2.

${ }^{60}$ Vale ainda salientar que o aperfeiçoamento que Kant defende não é uma eugênia das raças, mas tão somente o aperfeiçoamento moral de toda a espécie humana. Ou seja, esse aperfeiçoamente não se dá no âmbito genético ou biológico, mas sim, na esfera dos costumes, nas ações dita morais pelo imperativo categórico eregido pela prórpia razão humana.

${ }^{61}$ KANT. Immanuel. Fundamentação da metafísica dos costumes. Lisboa: Edições 70, 2011, p.52.
}

\begin{tabular}{|c|c|c|c|c|c|}
\hline intuitio & $\begin{array}{c}\text { ISSN } \\
1983-4012\end{array}$ & Porto Alegre & Vol.11 - No.2 & $\begin{array}{c}\text { Dezembro } \\
2018\end{array}$ & p.66-86 \\
\hline
\end{tabular}


humana vai além disso e é necessário ousadia para sair da tutela, seja de outro homem, seja de um livro; de qualquer coisa que nos impessa de pensar por nós mesmos.

Sendo assim, como afirma Bresolin, acerca da pedagogia kantiana:

A educação não garante, em nenhum momento, que o educando se torne um ser esclarecido, isto é, que realize o processo de esclarecimento (Aufklärung) de sair da menoridade e entrar na maioridade, uma vez que tal processo é uma decisão pessoal intrasnferível. No entanto, sem ela, é impossível que isso aconteça. ${ }^{62}$

E diz ainda a respeito da finalidade moral da teoria da educação de Kant: "Educar para a moral não significa que será ensinada uma moral preestabelecida para a criança, muito pelo contrário, serão oferecidas à criança as condições para que ela encontre, em si mesma a moral"63. Digo, Kant não pretende impor, por meio da educação, uma ideologia moral, mas, tão somente, uma educação que possibilite a conquista da autonomia do pensamento e da moralidade livre, isto é, a verdadeira moral ${ }^{64}$.

Portanto, se a razão não é apta bastante para guiar com segurança a vontade no que respeita aos seus objetos // e à satisfação de todas as nossas necessidades (que ela mesma - a razão - em parte multiplica), visto que um instinto natural inato levaria com muito maior certeza a este fim, e se, no entanto, a razão nos foi dada como faculdade prática, isto é, como faculdade que deve exercer influência sobre a vontade, então o seu verdadeiro destino deverá ser produzir uma vontade, não só boa quiçá como meio para outra intenção, mas uma vontade boa em si mesma, para o que a razão era absolutamente necessária, uma vez que a natureza de resto agiu em tudo com acerto na repartição das suas faculdades e talentos. Esta vontade não será na verdade o único bem nem o bem total, mas terá de ser contudo o bem supremo e a condição de tudo o mais, mesmo de toda a aspiração de felicidade. ${ }^{65}$

Sendo assim, apesar da educação ter papel decisivo na efevitação do aperfeiçoamento humano, pois contribui com o bom uso da razão e pode influênciar na postura do homem enquanto indivíduo de uma sociedade, não podemos excluir a responsabilidade individual de cada um buscar o seu próprio esclarecimento e autonomia moral, visto que cabe a cada um se libertar individualmene da tutela alheia. Ou seja, a educação favorece essa postura, mas não é garantia do

\footnotetext{
${ }^{62}$ BRESOLIN, Keberson. A filosofia da educação de Immanuel Kant: da disciplina à moralidade. Caxias do Sul: Educs, 2016, p. 80.

${ }^{63}$ BRESOLIN, Keberson. A filosofia da educação de Immanuel Kant: da disciplina à moralidade. Caxias do Sul: Educs, 2016, p.118.

${ }^{64}$ Uma moral que é imposta por uma autoridade e que seja coecitiva não pode ser considera verdeiramente moral visto que a moral é fundamenta pelas leis da liberdade e, não por princípio heterônomos.

${ }^{65}$ KANT, Immanuel. Fundamentação da metafísica dos costumes. Lisboa: Edições 70, 2011, p. 25 e 26.
}

\begin{tabular}{|c|c|l|l|c|c|}
\hline intuitio & $\begin{array}{c}\text { ISSN } \\
1983-4012\end{array}$ & Porto Alegre & Vol.11- $\mathrm{N}^{\circ} .2$ & $\begin{array}{c}\text { Dezembro } \\
2018\end{array}$ & p.66-86 \\
\hline
\end{tabular}


esclarecimento moral e nem isenta o homem indivídual de sua própria responsabilidade de seguir a sua inteira destinação.

\section{Considerações finais}

As críticas que o filósofo Immanuel Kant faz ao sistema educacional de sua época não se limitam ao período do Iluminismo. Na verdade, as questões colocadas por ele são extremamentes atuais. Uma das mais relevantes críticas feita por ele é o descaso para com a educação com fins a liberdade. Essa crítica também pode ser aplicada ao nosso sistema educacional atual, haja vista que muitos governantes não se preocupam com o desenvolvimento da liberdade e autonmia. $\mathrm{Na}$ realidade, são poucos os que se preocupam em refletir seriamente à respeito da filosofia da educação e à problemática educacional com fins ao desenvolvimento crítico. Pois, o que muitas vezes predomina nos sistemas educacionais é a perpertuação de planejamentos educacionais prontos de antemão e que são muitas vezes repetidos sem reflexão.

Por essa razão, estudar teorias educacionais de filósofos, como por exemplo, Immanuel Kant tende a contribuir para a reflexão e o debate acerca dos problemas da educação e de sua importância para a sociedade. E nesse caso, especificamente, Kant se caracteriza como um pensador que propõe uma teoria educacional pautada no aperfeiçoamento de toda humanidade à medida que ele almeja em seu sistema filosófico um propósito cosmopolita. Isto é, para Kant toda a história da humanidade e sua marcha educacional serve para cumprir o destino da natureza que é a perfeição humana, isto é, agir segundo as leis da liberdade. Kant também ressalta essa tese na segunda proposição da obra Idee zu einer allgemeinen Geschichte in weltbürgerlicher Absicht como podemos comprovar na seguinte citação: "No homem (como única criatura racional sobre a terra), as disposições naturais que visam o uso da sua razão devem desenvolver-se integralmente só na espécie, e não no indivíduo"66

No que concerne ao o problema que nos propomos a investigar (como a educação pode contribuir com o aperfeiçoamento da natureza humana? E, nessa perspectiva, quais os princípios que devem fundamentar uma educação que visa a inteira destinação da humanidade?), chegamos a seguinte conclusão: a educação pode contribuir com o aperfeiçoamento da natureza humana na medida que possibilita ao homem aprender a fazer bom uso de suas faculdades, da razão. E quanto aos princípios que devem fundamentar uma educação que objetiva esse fim se resumem

${ }^{66}$ KANT, Immanuel. Ideia de uma História Universal com um propósito Cosmopolita. Tradução: Artur Morão. Lusosofia: press, 2013, p.5.

\begin{tabular}{|c|c|l|l|c|c|}
\hline intuitio & $\begin{array}{c}\text { ISSN } \\
1983-4012\end{array}$ & Porto Alegre & Vol.11- $\mathrm{N}^{\circ} .2$ & $\begin{array}{c}\text { Dezembro } \\
2018\end{array}$ & p.66-86 \\
\hline
\end{tabular}


nos deveres para conosco e para com os demais, isto é, o ideal da dignidade humana. No entanto, para que a educação esteja respaldada nessa idea norteadora deve-se pensar em uma educação que busque o desenvolvimento da maioridade, autonomia e liberdade humana.

Portanto, a importância da educação para a formação da humanidade do homem é o seu papel imprescindível para a realização desse fim, visto que a educação tem a capacidade de desenvolver habilidades que favorecem esse aperfeiçoamento. Portanto, podemos afirmar que a hipotése do nosso trabalho (a educação, quando pautada no ideal de humanidade, é a chave do aperfeiçomento do homem enquanto espécie humana) é uma resposta plausível, considerando que é por meio do ideal de humanidade que a educação e o próprio homem pode formular um modelo a ser seguido.

\section{Referências}

BRESOLIN, Keberson. A filosofia da educação de Immanuel Kant: da disciplina à moralidade. Rio Grande do Sul: Educs, 2016.

CAMBI, Franco. História da pedagogia. Tradução Álvaro Lorencini. São Paulo: Fundação Editora da UNESP (FEU), 1999.

CARVALHO, Alonso Bezerra de. A filosofia da educação kantiana: educar para liberdade. In.: Unesp. Pró-reitoria de Graduação. (Org.). Caderno de formação: Formação de professores: Educação, cultura e desenvolvimento. São Paulo: Cultura Acadêmica, 2010, v. 2, p.43-59.

KANT, Immanuel. Sobre a pedagogia. Tradução Francisco C. Fontanella. Piracicaba: Editora Unimep, 1999.

. Resposta à pergunta: o que é o Esclarecimento? Textos Seletos. Tradução: Floriano de Sousa Fernandes. 3 ed. Rio de Janeiro: Editora Vozes, 2005.

Lusosofia: press, 2013.

. Ideia de uma História Universal com um propósito Cosmopolita. Tradução: Artur Morão.

Iluminuras, 2006.

. Antropologia de um ponto de vista pragmático. Tradução: Clélia Aparecida Martins. São Paulo:

Fundamentação da metafísica dos costumes. Lisboa: Edições 70, 2011.

Metafísica dos costumes. São Paulo: Eipro, 2008.

LA TAILlE, Y. de. A educação moral: Kant e Piaget. In.: Macedo, L. de. (Org.) Cinco estudos de educação moral. São Paulo: Casa do Psicólogo, 1996, p. 135-173.

OLIVEIRA, Mário Nogueira de. A educação na ética kantiana. São Paulo: Educação e Pesquisa, 2004, v. 30, p. 447460.

ROSA. Leonardo de Ross. Disciplia, o princípio da educação em Kant. Congresso Internacional de filosofia e educação, Caxias do Sul, 2010.

\begin{tabular}{|c|c|c|c|c|c|}
\hline intuitio & $\begin{array}{c}\text { ISSN } \\
1983-4012\end{array}$ & Porto Alegre & Vol.11- No.2 & $\begin{array}{c}\text { Dezembro } \\
2018\end{array}$ & p.66-86 \\
\hline
\end{tabular}

